\title{
NOTES ON THE OWLET MOTHS (NOCTUIDAE) OF SASKATCHEWAN
}

\author{
L.G. PUTNAM. 35 Kirk Crescent, Saskatoon, Saskatchewan. S7H 3B1
}

Among the Lepidoptera, the predominantly drab night-flying Owlet moths (Noctuidae) attract less attention than the glamourous day-flying butterflies. However, in Saskatchewan, the Noctuidae comprise quite a long and varied list of species. Their wing patterns and colour variations, not to mention the more subtle diagnostic characteristics sometimes needed, suffice to interest and challenge the specialist or hobbyist.

The first list of noctuid species of Saskatchewan known to the author was that prepared (unpublished) by Dr. K.M. King, an early Officer-in-Charge of the Dominion Entomological Laboratory at Saskatoon. This arose out of material captured during a lengthy period of light trapping begun in the 1920s. H. McDonald, formerly of the same laboratory, continued light trapping in his own research interests, thereby adding to the species records. With an intended focus on pests of brassicaceous oilseed crops (mostly canola, or rapeseed as it was then known), the author operated a trapping station for a decade near the village of Aylsham, in the northeastern part of the Agricultural part of the province, in the heart of a longestablished rapeseed growing area. Five species records new to Saskatchewan were added from this source, although these had been noted elsewhere in Western Canada. This brought the Saskatchewan list to about 342 species. That list was by no means complete ( $R$. Hooper, pers. comm.).

The concern on the part of the workers at the Dominion Entomological Laboratory, and later of those at the Entomology Section of the Agriculture Research Station at Saskatoon with the
Noctuidae, arose naturally from the several economically important species included in the family. The important subterranean cutworms are the Pale Western (Agrotis orthogonia Morr.), a pest of field crops in the open plains of the province, and the Red-backed Cutworm (Euxoa ochrogaster Gn.), a pest of crops in the "Park Belt" and northerly areas, and a wide-spread pest of gardens. Among the climbing cutworms, the Bertha Armyworm (Mamestra configurata Wlk.), a notorious pest of the oilseed crops flax and canola, is most notable. A pest of cereal grains, the True Armyworm (Pseudaletia unipuncta Haw.) has been destructive locally from time to time. The same applies to the Flax Bollworm (Heliothis ononis D. \& S.), the Alfalfa Looper (Autographa californica Speyer) and the Clover Cutworm (Scotogramma trifolii Rott.). Several species taken in Saskatchewan have ranked as pests elsewhere but have been of minor and infrequent consequence here. (See Putnam and Burgess for photos of some economic noctuids. ${ }^{3}$ )

The purpose of operating a lighttrapping station at Aylsham was less a species survey than an abundance survey of economic species. Of the 210 noctuid species identified from that point in the decade, only 53 were taken in each of the 10 years. The rest were identified as follows (number of years taken, followed by number of species in that category, in parenthesis): 9 yr. (25 spp.); 8 (10); 7 (11); $6(13) ; 5$ (19); 4 (7); 3 (16); 2 (30); and 1 (26). Of those species captured in only four or fewer years of the 10, the average number per year per species was three or less; those caught every year averaged 92 per species per year. Presumably this difference reflects relative abundance, 
although King pointed out that comparisons of abundance between species on the basis of light trap captures may be invalid. ${ }^{2}$

The total annual captures of those species that were identified every year, or most years, varied widely within the decade, consistent with population fluctuations typical of insects. None varied at such extremes as the moths of the Redbacked Cutworm. This species was taken in larger total numbers than any other at Aylsham. The extremes were 3, in 1965 , to 5834 , in 1969. The latter figure contributed by far the most to the 10-year total of 7564. The trend was irregularly downward from 1961 to '65, and upward from '65 to '69, crashing abruptly in 1970. Apparently, a decade is too brief a period to examine population trends exhaustively. Through the observations of McDonald, it is known that the Redbacked Cutworm is sensitive to soil surface conditions for oviposition, and that hatchling survival may be drastically affected by soil moisture conditions. The abundance of Red-backed Cutworms as noted at Aylsham, is in accord with its status as a pest in the "Park Belt" and northerly areas of Saskatchewan. On the other hand, the major subterranean cutworm of the open plains, the Pale Western was taken in seven years at about 4 moths per year, confirming the long-alleged regional distinction.

An apparently high abundance of Redbacked Cutworms during their flight period may reflect a high larval population earlier in the spring of the same year, but it is not necessarily the result of an extensive damaging outbreak. In the Bertha Armyworm, abundance vs. scarcity has to be judged in a frame of reference different from that of the Red-backed Cutworm. In the 10-year period, total annual captures of Bertha Armyworm varied form 3 to 31. Only after the decade proper, in 1971 in the flight period preceding the "great" outbreak of 1971 in the rapeseed crops across the province in that year, did captures at Aylsham reach a total of 91 . The general outbreak continued at about the same level in 1972, when 1,074 were captured using a more effective trap. Equivalent captures using the old-style trap may reasonably be estimated at 250 to 300.

King concluded that year-to-year differences in captures of a given species were indicative of actual population changes, ${ }^{2}$ but, as we have seen in the cases of the Red-backed Cutworm and the Bertha Armyworm the meaning of such changes has to be interpreted on the basis of the observer's experience with each species.

All those species taken in excess of an arbitrary average of 50 per year were isolated in a separate list, comprising 25 species taken every year, plus one taken in 9 years. In addition to the Red-backed Cutworms the moths of several cutworms common enough to have qualified for common names somewhere, were included in the list: The Dingy, Striped, Clover, Bristly, Glassy, Early and Spotted Cutworms. The Wheathead Armyworm, recorded as an outbreak species at least once in Saskatchewan, made the list. About eight other common-named cutworm moth species were identified at lower numbers.

It is commonly accepted, as claimed by Guppy, that the True Armyworm cannot winter in our latitudes, and therefore reaches Saskatchewan by immigration. ' It can produce two generations per season here, and the second would normally generate any larval outbreak occurring in cereals. If moths of this species immigrate, a question arises as to how many other species detected at Aylsham might have been immigrants, at least into the district if not into the province. The data shed no light on whether the species taken irregularly and in small numbers were scarce permanent residents, or not suscep- 
tible to trapping, or casual invaders. Traps using the more effective ultra violet fluorescent lamps instead of the 100-watt incandescents used during the designated decade might have shed some light on the issue, but would have made it necessary to examine about three times as many specimens, not to mention a greatly increased bulk of "junk" insects.

The order in which the species succeed each other in their first appearances at the trap, from the beginning to the end of the season, is a separate subject. It will mereIy be noted here that among the first are Lithophane thaxteri Grt. and Litholomia napaea Morr. They are also among the last to appear in the fall, and therefore mav be considered to winter in the moth stage. * Most other species in Saskatchewan have a diapause in the egg, larval or pupal stage, and hibernate in one of those.

Mr. C.G. Devlin, Technician, using the skills in the taxonomy of the Noctuidae acquired first under the direction of Dr. H. McDonald, played an essential role in the identification of material captured at Aylsham. It is a pleasure to acknowledge his contribution. Resort was regularly had to the reference collection of Noctuidae available at the Agriculture Canada Research Station at Saskatoon, where both the author and Devlin were employed when the work described was under way.

I GUPPY, J.C. 1961. Life history and behaviour of the armyworm Pseudaletia unipuncta (Haw.) (Lepidoptera: Noctuidae) in Eastern Ontario. The Canadian Entomologist 93:1141-1153.

2 KING, K.M. 1940. The light trap as an indicator of population trends in Noctuidae. Ph. D. Thesis, University of Minnesota (Unpublished).

3 PUTNAM, L.G., and L. BURGESS. 1979. Insect pests of rape and mustard. In: Insect pests and diseases of rape and mustard. Rapeseed Association of Canada Publ. No. 48.

* These species are in the subfamily Cucullinae. A number of other species in the same subfamily overwinter as adults in Saskatchewan, especially those in the following genera: Lithophane, Eupsilia, Xylena and Homoglaea. These can be collected as adults in both October and April. The provincial total for noctuid species now stands at 523. -- R. Hooper

\section{VARIEGATED FRITILLARY BREEDING AT THE PAS, MANITOBA}

WALTER KRIVDA, Box 864, The Pas, Manitoba. R9A $1 \mathrm{~K} 8$

There are only two species known in the genus Euptoieta - E. hegesia and E. claudia. The first is a jungle butterfly ranging into the United States. The second, the Variegated Fritillary, also originates in the new world tropics but migrates across the whole of the United States and most of Canada to reach The Pas in late June or early July. These are rare visits. Several years go by without one being seen. These migrants are small, worn examples which can be seen on the wing for a few weeks. They feed at dandelion blossoms.

Now and then a few specimens can be netted in The Pas area of a locally produced generation - originating from the eggs laid by the southern visitors. These are large dark specimens often remarkably mottled on the underside. Such specimens 